\title{
The School as a Platform for Addressing Health in Middle Childhood and Adolescence
}

\author{
Donald A. P. Bundy, Linda Schultz, Bachir Sarr, \\ Louise Banham, Peter Colenso, and Lesley Drake
}

\section{INTRODUCTION}

Health and nutrition programs targeted at school-age children are among the most ubiquitous of all public health programs worldwide. Since the inclusion of school health and nutrition (SHN) in the launch of the call for Education for All (EFA) in 2000, it has been difficult to find a country that is not attempting at some level to provide SHN services (Sarr and others 2017). It is estimated that more than 368 million schoolchildren are provided with school meals every day (World Food Programme 2016), and according to the World Health Organization (WHO) statistics (WHO 2015), 416 million school-age children were dewormed in 2015, which equals 63.2 percent of the target population of children in endemic areas; see chapter 29 in this volume (Ahuja and others 2017). These largely public efforts are variable in quality, and coverage is greatest in the richer countries, but the scale indicates public recognition of the willingness to invest in middle childhood and adolescence.

Health status affects cognitive ability, educational attainment, quality of life, and the ability to contribute to society. Some of the most common health conditions of childhood have consequences for education. SHN interventions can support vulnerable children throughout key stages of their development in middle childhood and adolescence. A set of priority school-based interventions, selected on the basis of cost-effectiveness, benefit-cost analysis, and rate of return, is described in chapter 25 in this volume (Fernandes and Aurino 2017).

Schools are a cost-effective platform for providing simple, safe, and effective health interventions to school-age children and adolescents (Horton and others 2017). Many of the health conditions that are most prevalent among poor students have important effects on educationcausing absenteeism, leading to grade repetition or dropout, and adversely affecting student achievement-and yet are easily preventable or treatable. With gains in enrollment achieved by the Millennium Development Goals, SHN interventions are important cross-sectoral collaborations between Ministries of Health and Education to promote health, cognition, and physical growth across the life course.

The education system is particularly well situated to promoting health among children and adolescents in poor communities without effective health systems who otherwise might not receive health interventions. There are typically more schools than health facilities in all income settings, and rural and poor areas are significantly more likely to have schools than health centers. The economies of scale, coupled with the efficiencies of using existing infrastructure and the potential to administer additional interventions through the same delivery mechanism, make SHN interventions 
particularly cost-effective. As a result, schools can reach an unprecedented number of children and adolescents and play a key role in national development efforts by improving both child health and education. Because schools are at the heart of all communities, we have an opportunity to use the school as a sustainable, scalable option for simple health service delivery.

This chapter explores the developmental rationale for improving the health of school-age children and the economic rationale for administering health interventions to school-age children (typically from ages 5 to 14 years) through existing educational systems as compared with the health system. Definitions of age groupings and age-specific terminology used in this volume can be found in chapter 1 (Bundy, de Silva, and others 2017).

\section{SCHOOL HEALTH AND NUTRITION}

SHN describes a wide range of interventions delivered through schools to improve education and health outcomes by enhancing nutrition, alleviating hunger, and preventing disease. SHN interventions can target the most common local health conditions that affect schoolage children and can be delivered by teachers and other proxies for the health system. Delivery of health interventions through schools enables children to take advantage of investments made in the education sector and improves country competitiveness, given that each increased year of schooling is associated with greater earning capacity and lower levels of mortality, illness, and health risks. As more children survive and thrive (figure 20.1), the role of schools becomes increasingly important.

Figure 20.1 Rate of Survival beyond Age Five Years

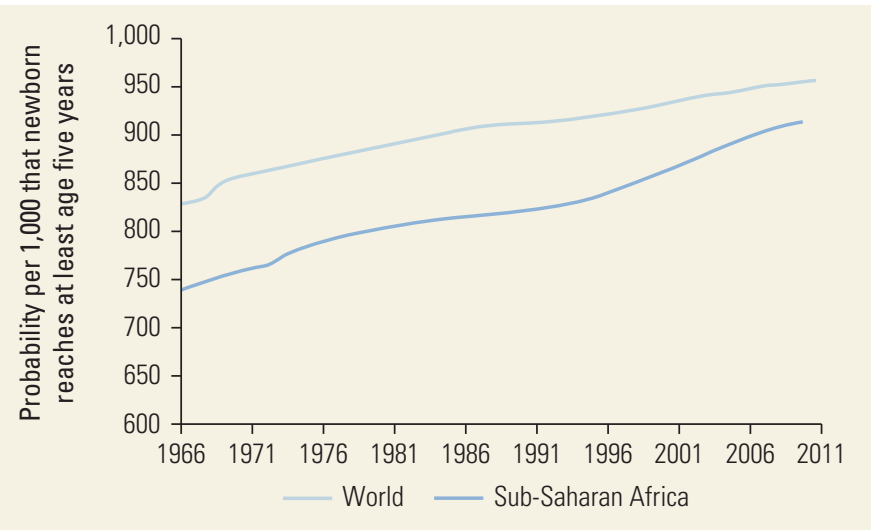

Source: World Bank 2016.

Note: Survival rate is the inverse of the under-five year mortality rate, which is the probability per 1,000 that a newborn will die before reaching age five years, subject to age-specific mortality rates for the specified year.
These programs have a long history. At the turn of the twentieth century, school feeding ${ }^{1}$ initiatives were among the first social welfare programs to emerge in highincome countries (Atkins 2007). Recognition that SHN benefits learning had been clear from the 1920s, when school-based deworming programs were instituted across the southern United States specifically to promote education and reduce poverty (Ettling 1981). By the 1980s, SHN programs had become ubiquitous in upper-middle-income countries and high-income countries. Change also began in the 1980s in low- and middle-income countries (LMICs) with a shift away from the traditional complex, medical-based approach, usually targeted to elite urban or boarding schools, and toward interventions targeted to the poorest schools.

Both the health and education communities have championed SHN in LMICs. The WHO's Ottawa Charter for Health Promotion, launched in 1986, provided momentum for global recognition of the importance of addressing health in the educational context (WHO 1986). This recognition was further propelled by the work of the WHO Expert Committee on Comprehensive School Health and Nutrition Education and Promotion in the mid-1990s. The WHO's Information Series on School Health and Nutrition, together with the United Nations Educational, Scientific and Cultural Organization (UNESCO) and Education Development Center, commenced in the late 1990s (WHO 1997). There was also an attempt to promote thinking around SHN at the 1990 World Education Forum in Jomtien, Thailand, but it was not until 10 years later that the concept gained traction in the global commitment to achieve EFA launched at the World Education Forum in Dakar, Senegal, in 2000. To strengthen the focus on SHN, several organizations, including UNESCO, the United Nations Children's Fund (UNICEF), the WHO, and the World Bank, used the Dakar Forum to launch an organizing framework entitled Focusing Resources on Effective School Health and Nutrition (FRESH). Since then, an increasing number of low- and lower-middle-income countries have adopted more comprehensive SHN policies with the specific aims of achieving EFA along with the education-specific Millennium Development Goals of universal basic education and gender equality in educational access (Bundy 2011). In Sub-Saharan Africa, the percentage of countries implementing programs that meet the minimum WHO Health Promoting School criteria of equity and effectiveness rose from 10 percent in 2000 to more than 80 percent in 2014 (Drake, Maier, and de Lind van Wijngaarden 2007) (figure 20.2). In Sub-Saharan Africa, the percentage of reproductive health service-supported programs rose from 10 percent to more than 70 percent, with an estimate of 80 percent in 2014. 
Figure 20.2 Expansion of School Health and Nutrition in Sub-Saharan Africa

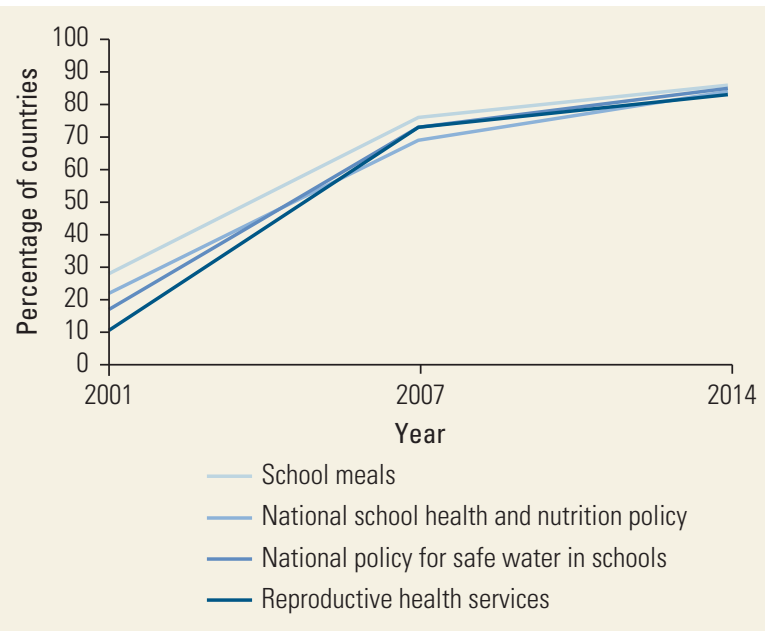

Source: Adapted from Drake, Maier, and de Lind van Wijngaarden 2007.

\section{HEALTHY CHILDREN, BETTER LEARNING}

SHN programming is increasingly recognized as a critical element for achieving universal access to education. Access to a school, provision of quality teaching and learning materials, and availability of trained teachers are necessary, but insufficient, to achieve good learning outcomes. Children also need to be healthy and regularly attending school to be able to benefit fully from the learning opportunities. Ill health can be the catalyst for extended absence or dropping out of school completely; malaria and worm infections can reduce enrollment; anemia can affect cognition, attention span, and learning; and the pain associated with tooth decay can affect both attendance and learning (chapters 11-16 of this volume; Benzian and others 2017; Brooker and others 2017; Bundy, Appleby, and others 2017; Drake, Fernandes, and others 2017; LaMontagne and others 2017; Lassi, Moin, and Bhutta 2017). The potential for school health interventions to shape physical and psychosocial health as well as education outcomes for youth has been explored to a greater extent in high-income countries, especially in the United States (Durlak, Weissberg, and Dymnicki 2011; Murray and others 2007; Shackleton and others 2016).

Some of the most prevalent health conditions of schoolage children affect children's education participation and learning outcomes significantly (table 20.1). Typical interventions and their target conditions include the following: deworming and worm infection; bednets and malaria; handwashing and bacterial infections; toothbrushing and dental caries; spectacles and refractive error; micronutrients and micronutrient deficiency; and food and hunger. Research has shown that the average IQ loss for children with these conditions can range from 3.7 IQ points per child with untreated worm infections to 6.0 IQ points for children with anemia. Together, these prevalent conditions are estimated to translate into the equivalent of between 200 million and 500 million years of school lost due to ill health in LMICs each year (Bundy 2011).

Interventions for these common health conditions can have long-term economic benefits. Estimates show that poor students in areas where these conditions are prevalent would gain the equivalent of $0.5-2.5$ extra years of schooling if their health benefited from appropriate interventions. Sustaining the benefits across multiple years of schooling could improve cognitive abilities by 0.25 standard deviations, on average; extrapolating the benefits of improved accumulation in human capital could translate to roughly a 5 percent increase in earning capacity over the life course; see chapter 29 in this volume (Ahuja and others 2017).

SHN interventions can enhance equity by supporting student participation and contributing to a reduction in the education achievement gap between well-performing and underperforming students. A study in South Africa found that children who score 0.25 standard deviations above the mean on grade 2 examinations were significantly more likely to complete grade 7 (figure 20.3). If schools that delivered health and nutrition interventions could raise examination scores, they may experience higher student retention, compared with schools without health programs.

Although better health alone cannot compensate for missed learning opportunities, it can provide children with the potential to take advantage of learning

Table 20.1 Estimates of the Global Cognitive Impact of Common Diseases of School-Age Children in LMICs

\begin{tabular}{lccccc}
\hline Common diseases & Prevalence (\%) & Total cases (millions) & I0 points lost per child & $\begin{array}{c}\text { Additional cases of } \\
\text { I0 }<70 \text { (millions) }\end{array}$ & $\begin{array}{c}\text { Lost years of } \\
\text { schooling (millions) }\end{array}$ \\
\hline Worms & 30 & 169 & 3.75 & 15.8 & 201 \\
Stunting & 52 & 292 & 3 & 21.6 & 284 \\
Anemia & 53 & 298 & 6 & 45.6 & 524 \\
\hline
\end{tabular}

Source: Bundy 2011.

Note: 10 = intelligence quotient; LMICs = low- and middle-income countries. 
Figure 20.3 Estimated School Dropout Rates, with and without School Health and Nutrition Interventions, in South Africa

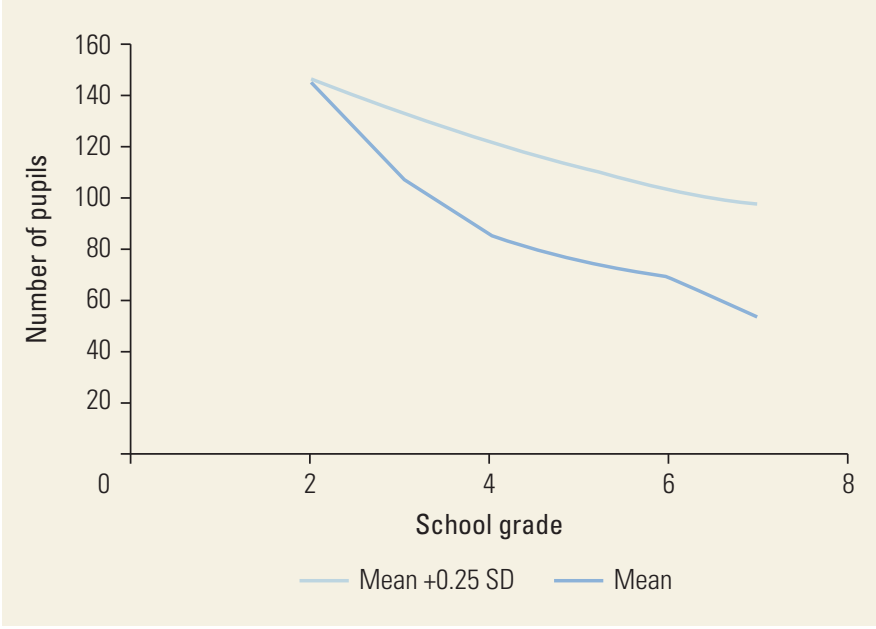

Source: Liddell and Rae 2001.

Note: $\mathrm{SD}=$ standard deviation. Students who score 0.25 SD higher on exams in grade 2 are more likely to complete grade 7 . If schools that delivered health and nutrition interventions could raise examination scores, they may experience higher student retention compared with schools without health programs. opportunities (Grigorenko and others 2006). Children are more ready to learn after treatment; they may be able to catch up with better-off peers if their improved learning potential can be used effectively in the classroom. The education sector is responsible for the quality of education delivered and for leveraging the investment it has already made.

A key message of this volume is that different types of health interventions are required at different stages in child and adolescent development. The accumulating evidence on the benefits of targeted interventions from middle childhood to late adolescence is summarized in chapter 6 in this volume (Bundy and Horton 2017); the potential impact of targeted intervention in school-age children is discussed in chapter 8 of this volume (Watkins and others 2017).

SHN and school feeding interventions build on the foundation of early child development interventions and exploit the accessibility of children in schools. Figure 20.4 demonstrates how the World Bank characterized the varied opportunities for health interventions at different life

Figure 20.4 Learning as a Lifelong Process

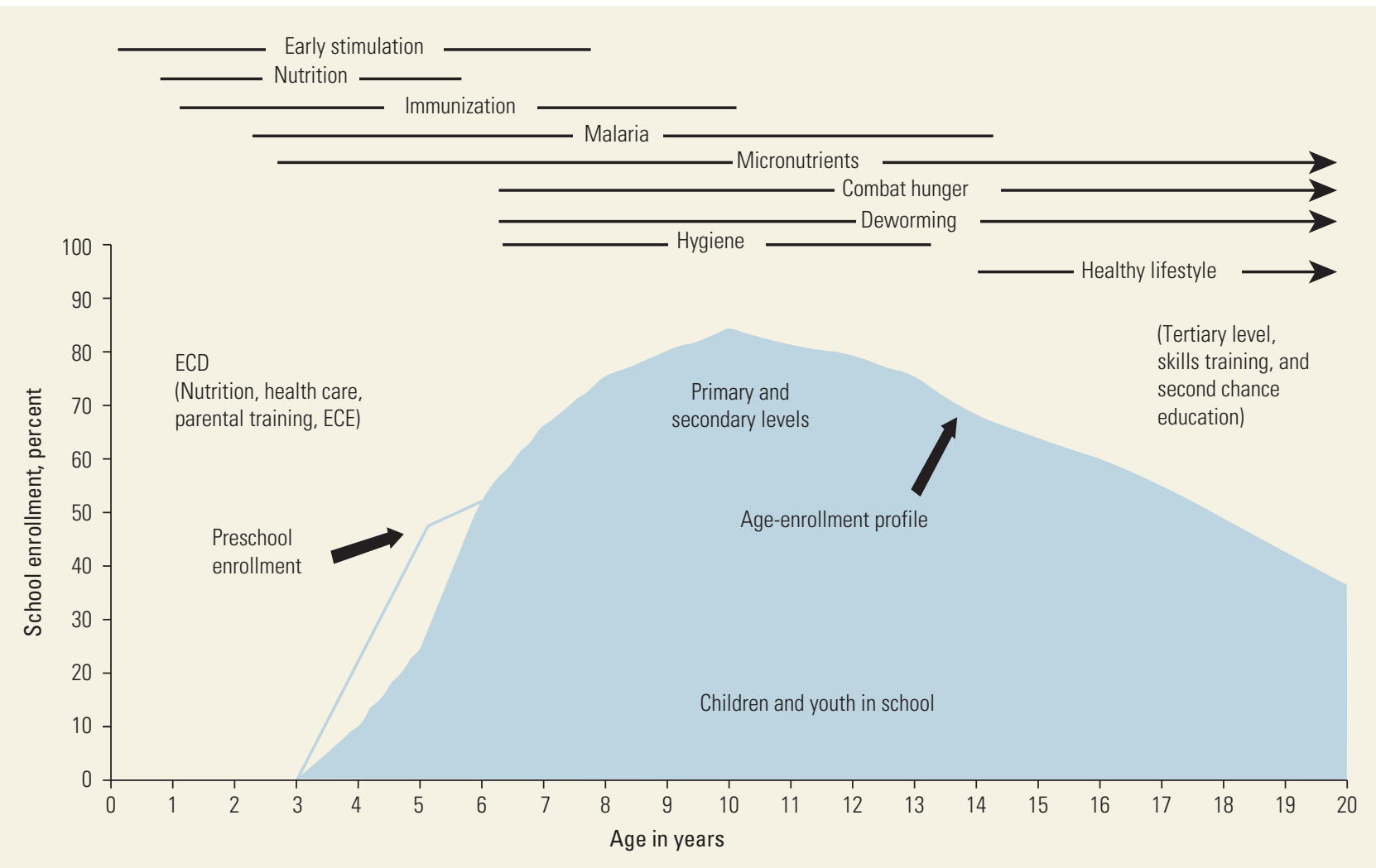

Source: Adapted from World Bank 2011, updated to include preschool enrollment; World Bank 2016.

Note: $\mathrm{ECD}$ = early child development; ECE = early childhood education. Rates of preschool enrollment by country group: 18.05 (low income), 49.56 (lower-middle income; reflects reported rate from 2012), 58.39 (middle income). The rates indicate the total enrollment in preprimary education, regardless of age, expressed as a percentage of the total population of official preprimary education age. 
stages as part of an education strategy. The figure indicates schematically when interventions might be particularly helpful. For example, early stimulation can help ensure school readiness; malaria prevention and education on bednet use, school feeding, and deworming treatments can help keep children in school by enhancing attendance and reducing dropout rates; and vision correction and skills-based health education, along with school feeding, might help improve learning by enhancing cognition and educational achievement (World Bank 2012).

\section{SCHOOLS AS ENTRY POINTS FOR HEALTH INTERVENTIONS}

Schools are one of the few institutions in poor communities that provide access to trained human resources. In contrast, the health systems in many LMICs experience multiple barriers, especially in costs and human resources, that limit their ability to reach beyond health facilities. Schools cannot replace health systems, which remain the formal avenue for health delivery, but education systems can complement health delivery mechanisms by providing outreach opportunities through schools. Even in LMICs, school-based interventions can be widely implemented by the education sector, with the health sector ensuring proper oversight and training of school staff (Bundy 2011).

School-based health programs have the potential to reach an estimated 575 million school-age children in low-income countries (UNESCO 2008). This opportunity is particularly relevant to Sub-Saharan Africa. Young people constitute the greatest proportion of the population, and this is the only region in which the number of young people continues to grow substantially (UNFPA 2012). It is also important that this is now a region in which most children attend school. As shown in figure 20.5, the percentage of the population that has enrolled in school, completed primary education, and moved on to secondary school has increased considerably during the past four decades, so that the proportion of school-going children and adolescents in Sub-Saharan Africa today approaches that of South Asia. Despite the increasing number of children in school, Sub-Saharan Africa has low enrollment rates compared with the rest of the world. Looking ahead, an unprecedented number of children are anticipated to be in school in this region as enrollment rates improve. Because most countries have SHN programs, opportunities exist to scale up the scope of services and tailor specific types of programs to local contexts. It is important to note that the high pupil-to-teacher ratio in many schools may discourage educators and the education sector from adding extra
Figure 20.5 Percentage of Population Enrolled in Primary School and Who Move on to Secondary School in South Asia and Sub-Saharan Africa, 1970 and 2015

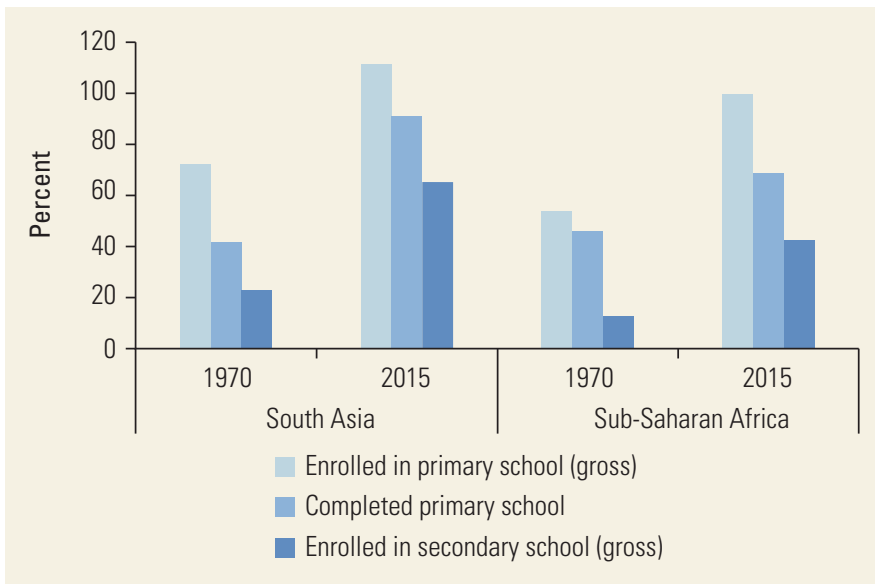

Source: World Bank 2016.

Note: Total enrollment, regardless of age, expressed as a percentage of the population of official primary or secondary education age. Gross enrollment rate can exceed 100 percent as a result of the inclusion of over-age and under-age students because of early or late school entrance and grade repetition.

Figure 20.6 Ratio of Primary School Teachers to Community Health Workers in 13 Low- and Lower-Middle-Income Countries, by GDP per Capita

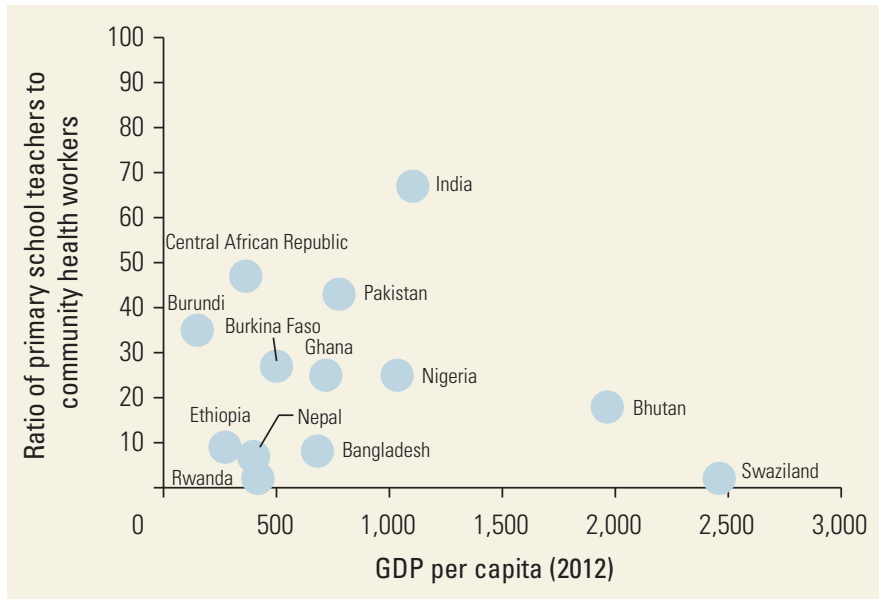

Sources: Data on the number of primary school teachers are from UNESCO Institute for Statistics (http://stats.uis.unesco.org); data on the number of community health workers are from the WHO Global Health Observatory Data Repository (http://apps.who.int/ghodata/); and GDP data are from World Bank 2016

Note: $\mathrm{GDP}=$ gross domestic product.

responsibilities that accompany SHN programming. Preservice sensitization and training can help educators recognize that healthy children learn better.

SHN systems build on existing infrastructure, curriculum opportunities, and teacher networks to accelerate implementation and reduce costs. There are more teachers than nurses and more schools than clinics, often by 
an order of magnitude. Figure 20.6 shows that the ratio of primary teachers to community health workers in several countries is in the range of 20:1 to $65: 1$; this relationship is only loosely related to gross domestic product (GDP). Including teachers-as the largest segment of the workforce and often community leaders-in public health activities can also broaden awareness of, and community commitment to, public health interventions.

\section{SCHOOL HEALTH AND NUTRITION PROGRAMS: PRO-POOR AND PRO-GIRL INTERVENTIONS}

SHN programs can help level the playing field for the most vulnerable students: the poor, the sick, and the malnourished. These are the children who require the greatest support throughout their schooling to minimize the risk of absenteeism and dropping out, but who generally have the least access to care and support (World Bank 2012). SHN and nutrition programs are pro-poor because the greatest benefits accrue to those children who are most affected at the outset (Bundy 2011). This pro-poor focus has also been increasingly emphasized in WHO SHN policies and practices (Tang and others 2009).

Poverty is a key consideration in the design of SHN and school feeding programs. The negative correlations between ill health, malnutrition, and income level are clearly demonstrated in both cross-country comparisons and individual country analyses (de Silva and others 2003), partly because low income and poverty promote disease and inadequate diets. Paradoxically, SHN programs are often most equitable when they are universal; mass delivery can help ensure that the interventions reach those poorest children who are more often systematically overlooked, especially by intervention programs that operate through diagnoses at health facilities.

However, the equity value of universal access within schools does not imply that there is no value in targeting poor communities. With few exceptions, the diseases that affect children and their education are most prevalent in poor countries, particularly in the poorest communities within those countries. As a result, targeting interventions to those communities most likely to benefit is cost-effective and a common characteristic of strong SHN programs. The benefits of targeting school feeding interventions is discussed in depth in chapter 12 in this volume (Drake, Fernandes, and others 2017). Lessons gleaned from country case studies can illustrate the strengths of different school feeding approaches in both program design and service delivery (Drake, Woolnough, and others 2016).
Girls and young women benefit particularly from SHN and school feeding programs because some of the most common health conditions affecting education are more prevalent in girls, and because gender-based vulnerability and exclusion can place girls at greater risk of ill health, neglect, and hunger (Bundy 2011). Deworming and iron supplementation offer particular benefits to girls because women and girls are, for physiological reasons, more likely to experience high rates of anemia. SHN programs draw children-especially girls-into schools and encourage them to stay (Gelli, Meir, and Espejo 2007). This dynamic is particularly relevant to achieving EFA; marginalized children, among whom girls are overrepresented, account for the majority of out-of-school children (UNESCO 2011). Moreover, improved health and increased educational attainment for young women can help delay age at first birth, which is associated with improved financial risk protection and enhanced intergenerational health outcomes; see chapter 28 in this volume (Verguet and others 2017).

Girls can benefit greatly from health promotion and life-skills lessons offered in schools. This benefit is exemplified with human immunodeficiency virus/ acquired immune deficiency syndrome (HIV/AIDS) education, particularly because young women in SubSaharan Africa are estimated to be two to seven times more likely to be infected with HIV than young men (MacPhail, Williams, and Campbell 2002). Health responses are more sustainable and have a greater reach when integrated into an existing framework, such as through a wider curriculum of health promotion (Jukes, Simmons, and Bundy 2008). Research shows that the most trusted source for young people to learn about HIV/AIDS is through schools and teachers (Boler 2003). A wide range of life skills and health promotion curriculum design, content, and implementation is available (Hargreaves and Boler 2006). Relatively simple lessons on skills-based health education can usefully address stigma and discrimination, and an integrated curriculum at a higher level of complexity can usefully influence protective health behaviors. Data show that for every extra year children remain in school HIV/AIDS rates are reduced (World Bank 2002). The years of school attended may not equate to greater attainment of skills-based health education because curriculum quality and extent of integration into the larger school framework vary widely (Hargreaves and others 2008; Jukes, Simmons, and Bundy 2008).

SHN programs may also work synergistically with conditional and unconditional social transfer programs; see chapter 7 in this volume (Alderman and 
others 2017) and chapter 12 in this volume (Drake, Fernandes, and others 2017). Take-home rations and conditional cash transfers can encourage girls to go to school; bursaries, which give rations directly to girl students, can encourage girls to stay in school (Chapman 2006). The broader value of these programs is discussed in chapter 23 in this volume (de Walque and others 2017).

Schools are an increasingly attractive and effective platform for reaching girls given that the gender gap in enrollment is closing in most countries. Figure 20.7 illustrates decreasing out-of-school rates between 1970 and 2010. The trend for girls is especially clear: between 1970 and 2010 the significant gap in enrollment of boys and girls was dramatically reduced, although a substantial number of children-more or less equally boys and girls-never enroll in school. Figures 20.8 and 20.9 provide a more nuanced look at the narrowing gender disparities in out-of-school children in South Asia and Sub-Saharan Africa, showing that greater change in enrollment among girls has occurred in South Asia.

Significant cross-country differences exist in gender disparities in enrollment rates based on historical experience and government policies. Data from five SubSaharan African countries are presented in figure 20.10. In Mozambique, the number of out-of-school children decreased significantly from 2000 to 2014, while gender gaps remained substantial. In contrast, the gender gap remained small in Ghana, while the trend was downward; in Niger, the number of out-of-school children remained relatively constant over the period, while the gender gap widened.

In some Sub-Saharan African countries, the numbers of out-of-school children have proved difficult to reduce; as a result, the observation that $\mathrm{SHN}$ programs can benefit out-of-school children becomes increasingly important. As documented in Guinea and Madagascar, many out-of-school children will take advantage of simple health services provided in schools, for example, deworming and micronutrient supplements; school feeding programs, especially takehome rations, have been shown to benefit siblings at home (Adelman and others 2008; Bundy and others 2009; Del Rosso and Marek 1996). Deworming programs in schools have been found to reach out-ofschool children at scale (Drake and others 2015) and reduce disease transmission in the community as a whole (Bundy and others 1990; Miguel and Kremer 2004). Although the benefits of SHN programs can extend beyond those who attend school, SHN programs are best considered in conjunction with other approaches to encouraging enrollment and attendance.
Figure 20.7 Global Out-of-School Children of Primary School Age, by Gender, 1970-2010

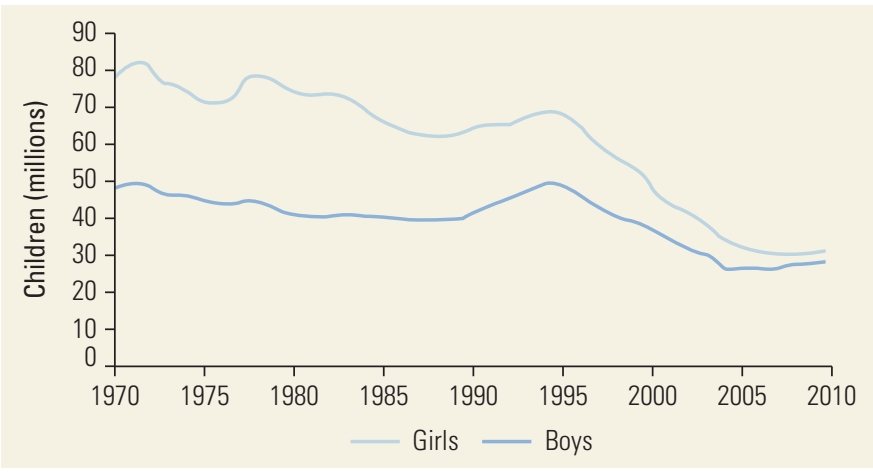

Source: World Bank 2016.

Note: The total number of boys and girls of primary school age who are not enrolled in either primary or secondary schools.

Figure 20.8 Out-of-School Children of Primary School Age in South Asia, 1975-2013

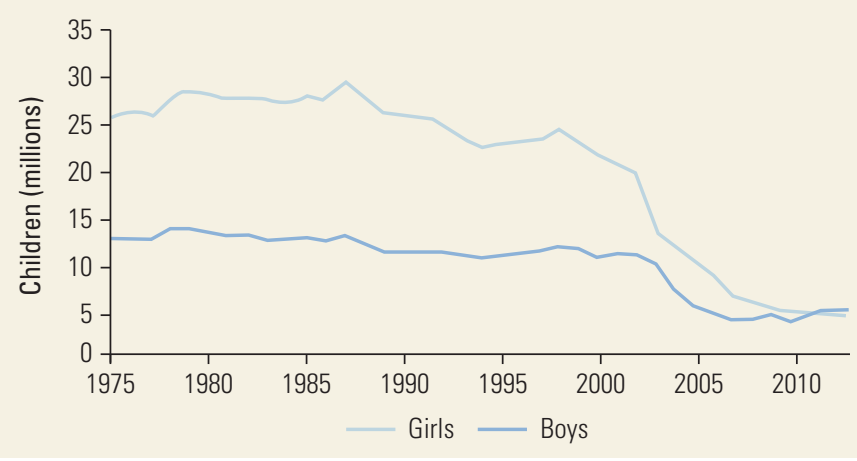

Source: World Bank 2016.

Note: The total number of boys and girls of primary school age who are not enrolled in either primary or secondary schools.

Figure 20.9 Out-of-School Children of Primary School Age in Sub-Saharan Africa, 1975-2013

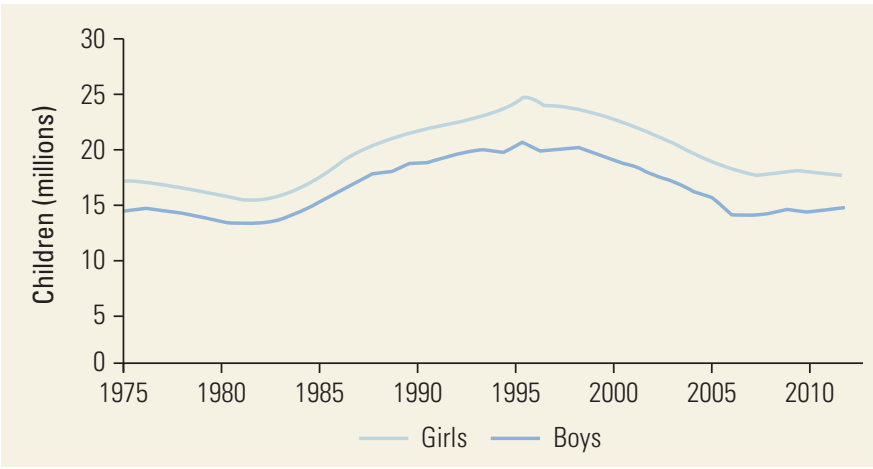

Source: World Bank 2016.

Note: The total number of boys and girls of primary school age who are not enrolled in either primary or secondary schools. 
Figure 20.10 Out-of-School Children of Primary School Age, in Five Countries, by Gender, 2000-14

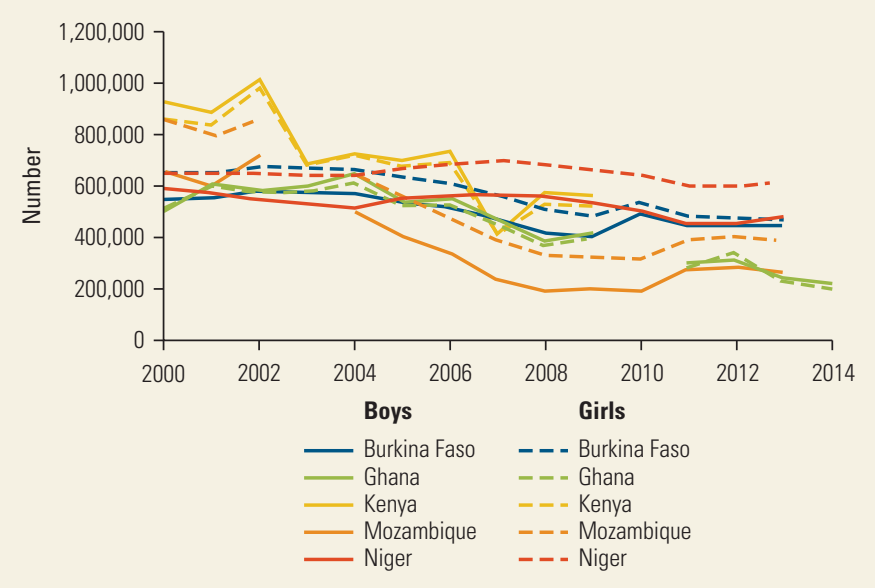

Source: World Bank 2016

Note: Out-of-school children of primary school age for specific countries. Figure shows the total number of boys and girls of primary school age who are not enrolled in primary or secondary schools. Gaps in the graphs are due to lack of data for those years.

It is important that out-of-school children have access to skills-based health education and life-skills development to prevent illnesses such as HIV/AIDS (Hargreaves and others 2008).

\section{DEFINING SECTOR ROLES}

The implementation, funding, and oversight of SHN programs do not fall squarely within either the education or the health sector. Rather, many approaches, stakeholders, and collaborations are involved in the delivery of health and nutrition services in schools. Diverse experiences suggest that existing programs highlight certain consistent roles played by government and nongovernmental agencies and other partners and stakeholders. It is clear that program success depends on the effective participation and support of strategic partnerships, especially with the beneficiaries and their parents or guardians (table 20.2).

In nearly every national SHN program, the Ministry of Education is the lead implementing agency, reflecting both the goal of SHN programs to improve educational achievement and the fact that the education system often provides the most complete existing infrastructure to reach school-age children. In successful programs this responsibility has been shared between the Ministry of Education and the Ministry of Health, particularly since the latter has the ultimate responsibility for the health of all children. However, collaboration across sectors is not easy, particularly given different institutional structures, operational mechanisms, and working cultures between different line ministries. Each sector needs to identify its respective role and responsibilities and present a coordinated plan of action to improve the health and education outcomes of children. Beyond the education and health ministries and nonstate actors, intersectoral collaboration is more complex. The starting point is usually the establishment of cross-sectoral working groups or steering committees at national, district, and local levels to coordinate actions and decision making (FRESH 2014). The understanding and recognition by the education and health sectors of each other's core business and priorities are also essential; the stronger and more explicit focus that the WHO places on achieving both health and education outcomes can facilitate collaboration between health promotion practitioners and teachers.

Successful multisector school-based health service delivery includes referral and treatment opportunities that extend beyond the school platform. School-based responses to the various diseases affecting school-age children vary depending on the nature of the treatment required. For example, there is a clear policy context for integrating the identification and referral of refractive error into wider SHN programs. It is essential that school-based vision screening programs include screening and referral at the primary level; refraction and optical dispensing at the district level; and supported advanced care, including pediatric and contact lens services, at the tertiary health care level, although the costs increase and feasibility decreases with each step away from the primary level (World Bank 2012). See chapter 17 in this volume (Graham and others 2017) for a more detailed look at schoolbased vision programming.

SHN programs offer a compelling case for public sector investment and interventions. First, these interventions may create externalities whereby external benefits accrue to people other than treated individuals. For example, deworming programs reduce the intensity of infection in untreated children in schools, in neighboring schools, and in siblings of those treated at schools (Miguel and Kremer 2004). Second, some health interventions are pure public goods-all school-age children are eligible to access these services and there is typically little private demand for general preventive measures. Accordingly, the private sector is unlikely to compete to deliver these goods and services. SHN programs are most likely to achieve universal coverage and be sustainable when they are under the jurisdiction of the public sector and integrated into national education sector plans (ESPs). 
Table 20.2 Comparison of Roles Played by Government Agencies, Partners, and Stakeholders in School Health and Nutrition Programs

\begin{tabular}{|c|c|c|}
\hline Partner & Roles & Comments \\
\hline Ministry of Education & $\begin{array}{l}\text { - Lead implementing agency } \\
\text { - Lead financial resource } \\
\text { - Education sector policy }\end{array}$ & $\begin{array}{l}\text { - Health and nutrition of schoolchildren is a priority for EFA. } \\
\text { - Education policy defines school environment, curriculum, duties } \\
\text { of teachers. } \\
\text { - Education system has a pervasive infrastructure for reaching } \\
\text { teachers and school-age children. }\end{array}$ \\
\hline Ministry of Health & $\begin{array}{l}\text { - Lead technical agency } \\
\text { - Health sector policy }\end{array}$ & $\begin{array}{l}\text { - Health of school-age children has lower priority than clinical } \\
\text { services and infant health. } \\
\text { - Health policy defines role of teachers in service delivery and } \\
\text { how health materials are procured. }\end{array}$ \\
\hline $\begin{array}{l}\text { Other public sector agencies (for } \\
\text { example, ministries of welfare, social } \\
\text { affairs, local government, agriculture) }\end{array}$ & $\begin{array}{l}\text { - Support education and health systems } \\
\text { - Fund holders }\end{array}$ & $\begin{array}{l}\text { - Ministries of local government are often fund holders for teachers } \\
\text { and schools, as well as for clinics and health agents. } \\
\text { - Ministries of welfare and social affairs provide mechanisms for } \\
\text { the provision of social funds. }\end{array}$ \\
\hline $\begin{array}{l}\text { Private sector (for example, health } \\
\text { services, pharmaceuticals, publications) }\end{array}$ & $\begin{array}{l}\text { - Specialist service delivery } \\
\text { - Materials provision }\end{array}$ & $\begin{array}{l}\text { - Major role in drug procurement and production of training } \\
\text { materials. } \\
\text { - Specialist roles in health diagnostics. }\end{array}$ \\
\hline $\begin{array}{l}\text { Civil society (for example, NGOs, FBOs, } \\
\text { PTAs) }\end{array}$ & $\begin{array}{l}\text { - Training and supervision } \\
\text { - Local resource provision }\end{array}$ & $\begin{array}{l}\text { - At the local level, serve as gatekeepers and fund holders; may } \\
\text { also target implementation. } \\
\text { - Offer additional resource streams, particularly through INGOs. }\end{array}$ \\
\hline $\begin{array}{l}\text { Teachers associations, local community } \\
\text { (for example, children, teachers, } \\
\text { parents) }\end{array}$ & $\begin{array}{l}\text { - Define teachers' roles } \\
\text { - Partners in implementation } \\
\text { - Define acceptability of curriculum } \\
\text { - Supplement resources }\end{array}$ & $\begin{array}{l}\text { - School health programs demand an expanded role for teachers. } \\
\text { - Gatekeepers for both the content of health education (especially } \\
\text { moral and sexual content) and the role of nonhealth agents } \\
\text { (especially teachers) in health service delivery. Pupils are active } \\
\text { participants in all aspects of the process at the school level. } \\
\text { - Communities supplement program finances at the margins. }\end{array}$ \\
\hline
\end{tabular}

Source: Jukes, Drake, and Bundy 2008.

Note: EFA = Education for All; FBO = faith-based organization; INGO = international nongovernmental organization; NGO = nongovernmental organization; PTA = parent-teacher association.

\section{ECONOMIC RATIONALE FOR SCHOOL-BASED HEALTH INTERVENTIONS}

In the complex set of conditions required for children to learn well, improved health can be one of the simplest and cheapest conditions to achieve (World Bank 2012). The focus of this economic rationale is on conditions for which there are existing interventions that are sufficiently safe, simple, and well evaluated to be appropriate for education sector implementation through schools, typically with health sector supervision.

Several factors support the economic rationale for schools as a platform for the delivery of health interventions. One of the main factors is the potential savings offered by school systems, rather than health systems, as the delivery mechanism. From this perspective, schools provide a preexisting mechanism, so costs are marginal; they also provide a system that as part of its primary educational purpose aims to be sustainable and pervasive, reach disadvantaged children, and promote social equity. Tailoring and targeting the types of interventions to local contexts lies at the heart of practical success. Targeting reduces costs and facilitates management; it may optimize outcomes.

Education sector spending exceeds public health spending in most LMICs. In Ghana, Mozambique, and Niger, for example, public expenditures for education are more than double those for public health (figure 20.11). The higher investment in the education sector relative to the health sector is reflected in the greater number of schools and teachers versus health centers and health workers in communities (see figure 20.6). 
Figure 20.11 Expenditures on Education versus Health as a Proportion of GDP, 2013

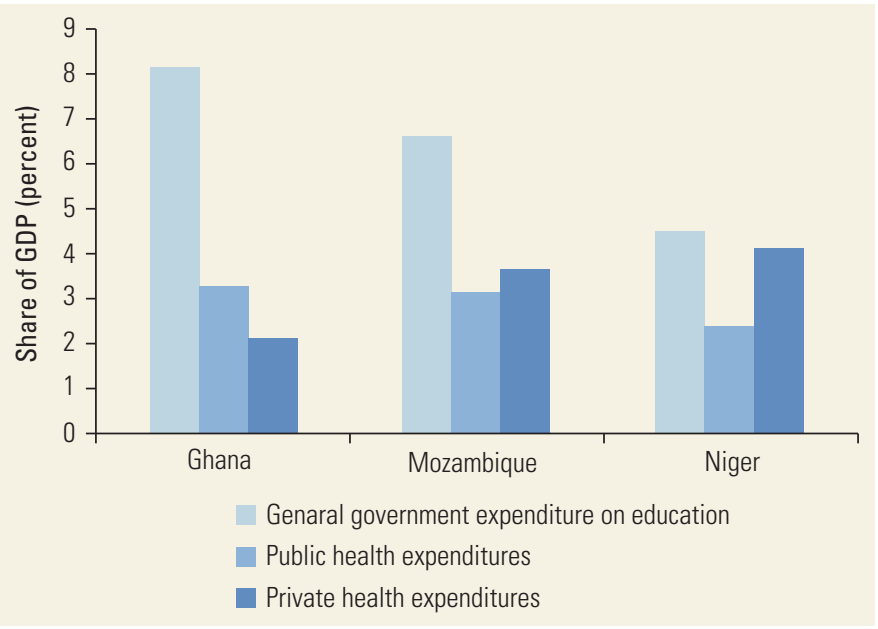

Source: World Bank 2016.

Note: GDP = gross domestic product. Total health expenditure is the sum of public and private health expenditure. It covers the provision of preventive and curative health services, family planning activities, nutrition activities, and emergency aid designated for health; it does not include provision of water and sanitation. General government expenditure on education (current, capital, and transfers) is expressed as a percentage of GDP. It includes expenditure funded by transfers from international sources to government. General government usually refers to local, regional, and central governments. Data are more readily available (as are world and regional estimates) for health than for education.

The large share of the population that school-age children represent and the high percentage of children that attend school imply significant economies of scale in the cost of delivering school-based health interventions. The economies of scale can be expected to be larger for interventions with small variable or marginal costs, that is, the cost of treating an additional child. School-based health interventions may also have fixed costs for establishing infrastructure, staffing, government capacity, intersectoral policies, and monitoring systems.

The rationale for school-based health interventions is also stronger for interventions that address prevalent conditions in populations (see table 20.1). In this case, the expected benefits are higher per dollar invested. Targeting school-based health interventions to children at greater risk may lead to greater benefits, but it may also lead to higher costs, depending on how the targeting is achieved.

\section{COMPARATIVE COST-EFFECTIVENESS OF DELIVERING HEALTH INTERVENTIONS THROUGH SCHOOLS}

Schools offer advantages over community and primary health center platforms. Chapter 25 in this volume presents an essential package of low-cost health interventions that can be delivered effectively in LMICs through schools (Fernandes and Aurino 2017). The analysis suggests that the economic benefits as measured by the returns to health and education outweigh the costs, while remaining affordable within government budget constraints. The essential package includes targeted school meals with micronutrient fortification, education on malaria prevention and oral hygiene, deworming treatment, screening for refractive error, and appropriate immunization.

The cost savings of delivering simple and safe interventions through schools can be illustrated in deworming and screening for refractive error. For example, delivery of mass administration of deworming treatment through schools (not including the cost of treatment because it is currently donated for schoolchildren) is estimated to cost US\$0.03-US\$0.04 per child per year, compared with US\$0.21-US\$0.51 through mobile health teams coordinated by primary health centers (Guyatt 2003). Screening costs for refractive error and provision of glasses through area hospitals were estimated to be US\$8.17, but the cost drops to US\$2-US\$3 if the screening is provided by mobile teams dispatched to schools following screening by teachers (Baltussen, Naus, and Limburg 2009; Graham and others 2017) (table 20.3). With minimal training combined with access to periodic supervision and support, school teachers can safely administer pills or screen children for health conditions of interest, limiting the time requirement and cost of access to skilled health personnel.

The presence of children at school obviates the need to draw children to another point of service at regular intervals or for mobile health teams to travel to reach them. Furthermore, the implementation of multiple interventions through the same delivery system allows for shared costs and efficiencies, for example, for teacher training. The effectiveness of primary health centers is contingent on the target population coming to clinics to receive the interventions, which can be a significant time

Table 20.3 Essential Package of School-Based Health Interventions, 2012 U.S. dollars

\begin{tabular}{lc}
\hline & Annual cost per child per year (\$) \\
\hline School meals & 44 \\
MNP supplementation & 3 \\
Malaria & $2-3$ \\
Refractive error screening & $2-3$ \\
Toothbrush provision & 0.50 \\
HPV vaccine & 2 \\
Tetanus toxoid vaccine & 0.40 \\
\hline
\end{tabular}

Source: Fernandes and Aurino 2017.

Note: $\mathrm{HPV}=$ human papillomavirus; $\mathrm{MNP}=$ micronutrient powder 
and cost burden on poorer families and especially challenging for interventions with multiple dosages, such as the human papillomavirus (HPV) vaccine, and for the school-age population; see chapter 15 in this volume (LaMontagne and others 2017). The economic analysis of the effect of health interventions on improved education attainment is discussed in chapter 22 in this volume (Plaut and others 2017).

\section{CONTEXT FRAMING AND POLICY FRAMEWORK}

Creating and refining an SHN program involves a series of policy decisions, especially how to work effectively across sectors and how to select interventions to include. Fortunately, two policy tools track some of the decisions that countries made in developing their SHN programs.

- The FRESH framework was introduced at the beginning of LMIC programming in this area and is still widely used. Its primary purpose was to provide a policy framework to support the start-up of new programs or the strengthening of existing programs.

- The Systems Approach for Better Education Results (SABER) was introduced more than a decade later as a mechanism for refining the policy environment of existing programs. The emergence of this tool reflects the need created by the remarkable proliferation of new school health and school feeding programs in LMICs.

\section{FRESH}

The use of schools as a platform for delivering SHN interventions was accelerated by the launch of the FRESH framework at the World Education Forum in 2000, by a multi-agency partnership that included UNESCO, UNICEF, the WHO, the World Food Programme, and the World Bank (Sarr and others 2017).

FRESH is a comprehensive, evidence-based framework that promotes better education through health interventions delivered by schools and is supported by an international consensus among partners and stakeholders. The FRESH framework offers strategic guidance to ensure that program implementation is standardized and evidence based (World Bank 2012). It lays the foundation for effective and equitable SHN programs and consists conceptually of four mutually reinforcing pillars (FRESH 2014):

- Pillar 1: Health-related school policies. Healthand nutrition-related school policies that are nondiscriminatory, protective, inclusive, and gender sensitive to promote the physical and psychosocial health of children, teachers, and school staff

- Pillar 2: Safe learning environment. Access to safe water and provision of separate sanitation facilities for girls, boys, and teachers; a safe, healthy, clean, and emotionally supportive environment that fosters children's ability to attend school, pay attention, and learn

- Pillar 3: Skill-based health education. Life-skills education that addresses health, nutrition, and hygiene issues with knowledge, attitudes, and skills to promote positive behaviors

- Pillar 4: School-based health and nutrition services. Simple, safe, and familiar health and nutrition services that can be delivered cost-effectively in schools, and increased access to youth-friendly clinics

All four of these components are necessary for a successful program. They can be implemented effectively only if they are supported by strategic partnerships between (1) the health and education sectors, especially teachers and health workers; (2) schools and their respective communities; and (3) pupils' awareness and participation. Figure 20.12 provides an illustrative example of the mutually reinforcing nature of the four FRESH pillars.

Governments that sought EFA outcomes also sought to mainstream programs based on these pillars into their national ESPs. Typically, ESPs reflect both expected budgetary and capacity needs, and are developed in consultation with key external and national stakeholders and partners. Analysis of the country ESPs provides insight into the relevance and prioritization of specific SHN issues by national governments. A comparison between the content of ESPs that were developed immediately following the launch of FRESH and those developed 15 years later provides an indication of how SHN programs have been mainstreamed into education systems. Figure 20.13 illustrates the proportion of countries seeking financing for each of the four pillars of FRESH at the two time points for a set of 25 countries in Sub-Saharan Africa. Countries include Benin, Burkina Faso, Burundi, Cameroon, the Central African Republic, Chad, Eritrea, Ethiopia, The Gambia, Ghana, Guinea, Guinea Bissau, Kenya, Liberia, Madagascar, Mali, Mauritania, Mozambique, the Democratic Republic of Congo, Rwanda, Senegal, Togo, Uganda, Zambia, and Zimbabwe.

The share of ESPs seeking financing for policy pillar 1 is low at both times, reflecting the long-term nature of the policy planning cycle and the typically fixed, nonrecurrent cost of implementing policy change. 


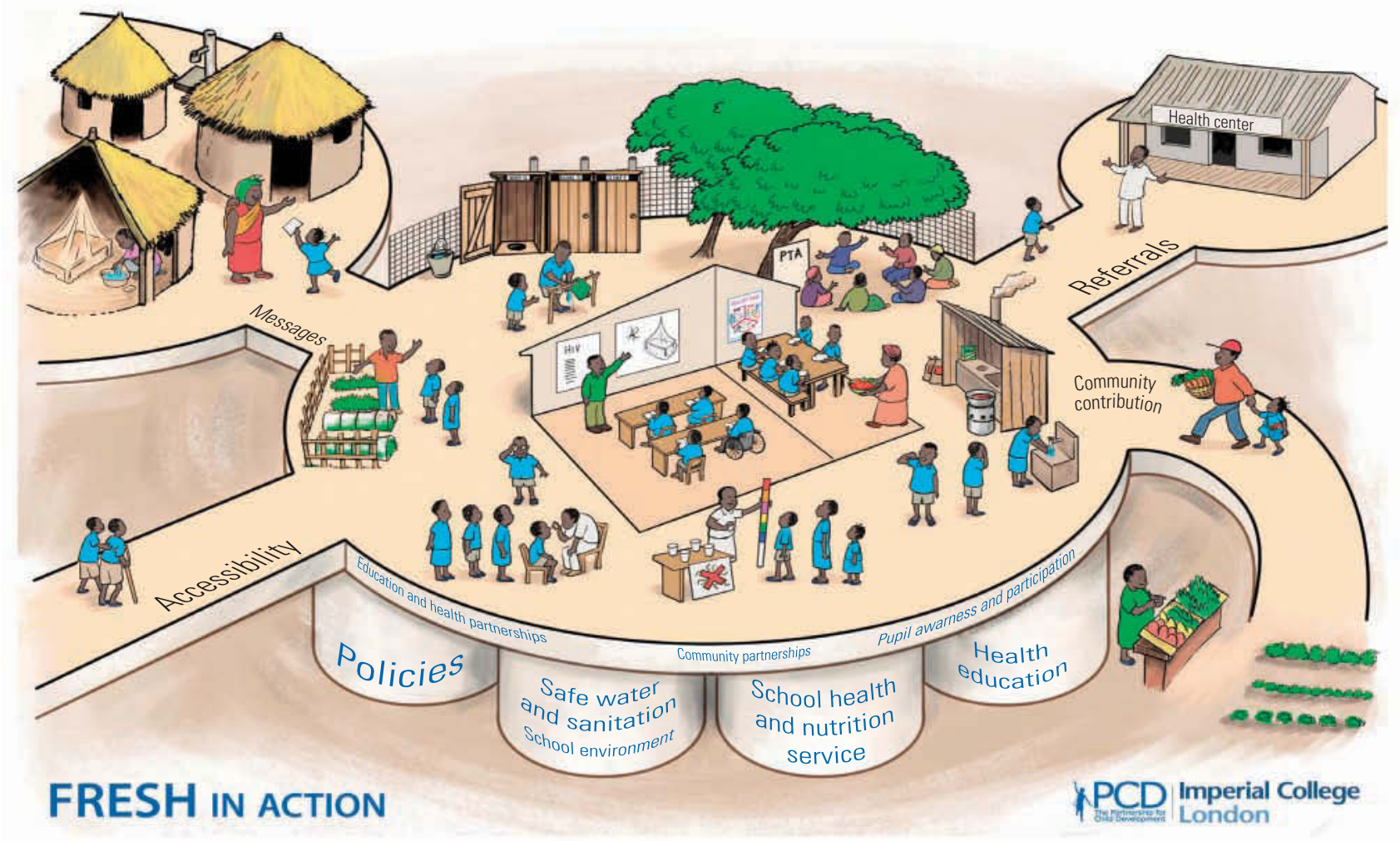

Source: (c) Partnership for Child Development. Used with the permission of Partnership for Child Development. Further permission required for reuse.

Figure 20.13 Reflection of Funding Prioritized for FRESH Pillars in Education Sector Plans from 25 Countries in Sub-Saharan Africa, 2001-15

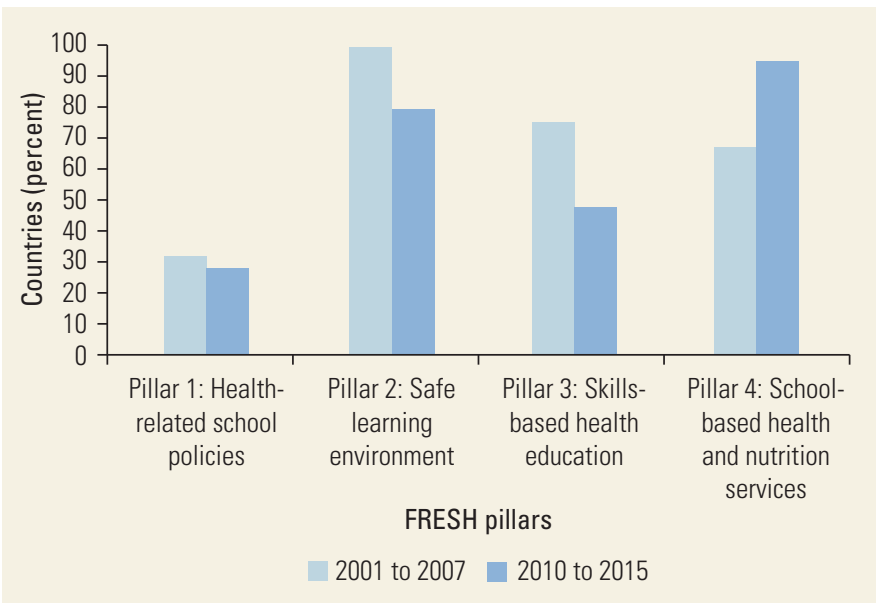

Source: Sarr and others 2017.

Note: FRESH = Focusing Resources on Effective School Health; UNESCO = United Nations Educational, Scientific and Cultural Organization. The dates for each period correspond to the date when the education sector plan (ESP) was published. ESPs set country priorities for the sector and typically reflect funding needs for 5 to 10 years. They are developed by governments in consultation with relevant stakeholders. ESPs from the earlier period were obtained from the UNESCO Planipolis portal, while ESPs from the later period were obtained from the Global Partnership for Education website.
In contrast, infrastructure and service costs, reflected under pillars 2 and 4, respectively, have a substantial recurrent component, which is reflected in the large proportion of countries seeking financing for these pillars at both times. Pillar 2 also reflects the focus on building new schools to support EFA, hence its inclusion in the ESPs for all countries in the earlier period and to a lesser degree in the later period, perhaps reflecting investment in additional water and sanitation facilities and a new focus on menstrual hygiene management. Pillar 3 in the 2000s in Sub-Saharan Africa was focused on HIV/AIDS prevention education. In the early period, this intervention was given special emphasis by the regional Accelerate initiative, in which most countries participated. As the HIV/AIDS epidemic waned, financing for pillar 3 declined (Sarr and others 2017).

Perhaps the most important consequence of FRESH has been to offer a common point of entry for new efforts to improve health in schools. This is important because over time SHN programs can address issues that both the education and health sectors are unfamiliar with and that are intrinsically multisectoral. 
The FRESH framework remains a driver of new SHN programming and has provided a common platform upon which to build agency-specific programs. Chapter 17 in this volume (Graham and others 2017) discusses how countries have used the FRESH framework to guide education that is inclusive for children with disabilities.

\section{SABER}

The degree to which SHN in practice is embedded in the education sector can be benchmarked with the SABER tool. The SABER tool was developed by a partnership led by the World Bank (2012) and was based on the FRESH framework. The tool consists of a structured questionnaire whose responses are determined based on consultation with representatives from relevant ministries, including Ministries of Education, Health, and Social Protection. One of the domains developed for SABER is SHN programming, with a large subcomponent for analysis of school feeding programs.

The SABER School Health and Nutrition and School Feeding diagnostic tools provide a snapshot of the development status of their related policies in countries. Specifically, SABER assists governments in assessing the quality of their SHN and school feeding programs and progress in implementing each indicator, and it benchmarks them against other programs and education domains. As such, SABER inspires and supports policy dialogue and reform, and lays the groundwork for a deeper analysis of the implementation of these frameworks. The SABER School Health and Nutrition and School Feeding rubric frameworks help ensure that when possible, schools can serve as entry points for health care for school-age children (World Bank 2012).

Figure 20.14 presents findings from an analysis of select indicators from SABER SHN reports from 16 LMICs published between 2011 and 2013, using the four pillars of FRESH as the guiding principle.

The results indicate that 13 of the 16 countries have national SHN policies; more than 50 percent have water, sanitation, and handwashing standards in place; 12 of the 16 countries implementing SHN services had specific recurrent budget lines to support delivery. In addition, gender-responsive policies, skills, and services were highlighted in SABER reports from 10 of the 16 countries.

Approaches to school feeding and SHN, as well as different routes to educational success, can be very diverse. No single set of policy options will be relevant to all countries. In developing national and subnational policies-and there are always trade-offs in the choices
Figure 20.14 Reflection of FRESH Pillars in School Health and Nutrition Practices in 16 Countries

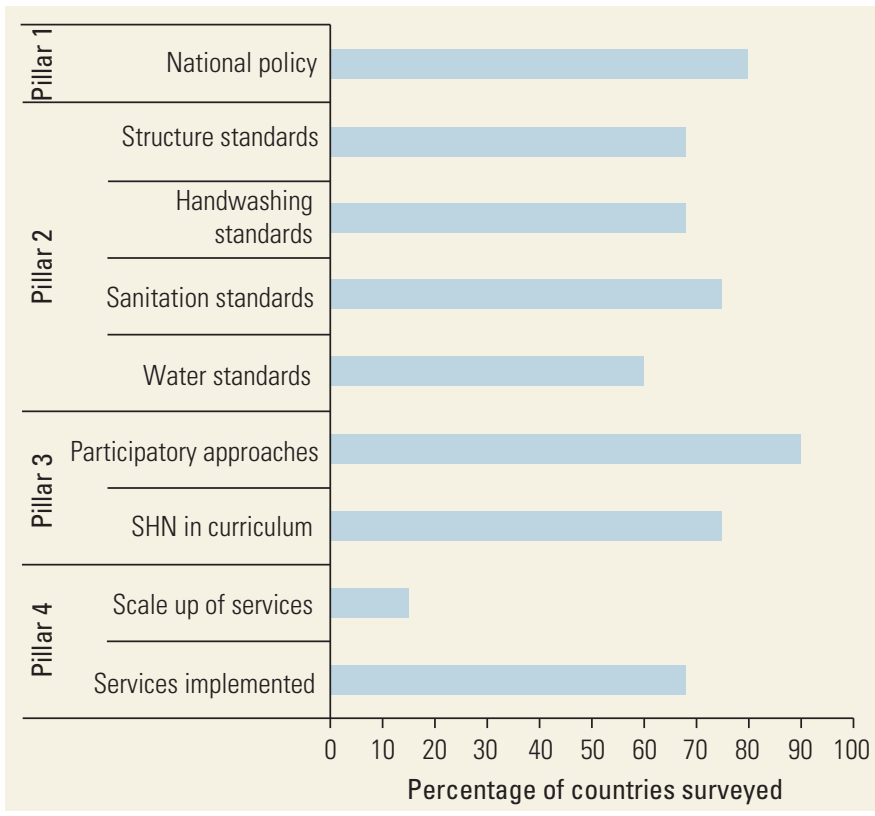

Source: Sarr and others 2017.

Note: FRESH = Focusing Resources on Effective School Health; SABER = Systems Approach for Better Education Results; $S H N$ = school health and nutrition. Indicators from SABER School Health and Nutrition report from 16 countries conducted between 2011 and 2013. Countries comprise Benin, Cape Verde, Côte d'Ivoire, Ethiopia, Ghana, Kenya, Madagascar, Malawi, Mali, Niger, Nigeria, Rwanda, Senegal, Tanzania, Uganda, and Zanzibar.

made-SABER helps identify common policy and institutional threads that run through most of the more successful experiences, such as the following:

- Focus on education outcomes

- Multisectoral policy and a memorandum of understanding between health and education sectors, backed by strong senior leadership from politicians and senior officials

- Information dissemination and consultation with local communities (World Bank 2012)

\section{Other School Health and Nutrition Policy Tools}

Other tools for policy making on SHN programs are available, in addition to FRESH and SABER. The School Health Policies and Practices Survey, the Global Schoolbased Student Health Survey (GSHS), and the Health Behavior in School-aged Children Survey (HBSC) are three such tools.

The School Health Policies and Practices Survey was developed by the WHO in collaboration with the U.S. Centers for Disease Control and Prevention (WHO and 
CDC, n.d.). The survey aims to assess the status of school health policies and practices in primary and secondary schools. It is administered through a questionnaire for school principals or head teachers. There are 150 questions divided into six content areas: general school information, healthy and safe school environment, health services, nutrition services, health education, and physical education.

The self-administered GSHS, similarly developed by the WHO and the U.S. CDC, is designed to help countries measure and assess the behavioral risk and protective factors among students ages 13-15 years. The data collected through the survey help set priorities, establish programs, advocate for resources, and allow for comparison across countries. It is a school-based questionnaire survey, managed by a survey coordinator who is appointed through the Ministries of Health and Education. Ten key topics covered include alcohol use, dietary behaviors, drug use, hygiene, mental health, physical activity, protective factors, sexual behaviors, tobacco use, and violence and unintended injury. To date, some 110 countries in all six WHO regions have either implemented the GSHS or are in the process of doing so (WHO 2016a). Of the 110 countries, only 3 are in Europe.

The HBSC is the primary behavioral survey administered in the WHO European Region for this target population. HBSC collects data every four years on the health and well-being, social environments, and health behaviors of boys and girls ages 11, 13, and 15 years through self-administered questionnaires in classrooms. The key content areas covered by the GSHS and HBSC surveys are similar, while the HBSC survey also includes a focus on social and economic determinants. To date, 44 countries and regions across Europe and North America have been involved in the HBSC survey (WHO 2016b).

\section{CONCLUSIONS}

The school system offers a number of advantages as a health delivery system in low-income countries. Building on an existing and pervasive infrastructure can reduce start-up costs, accelerate program implementation, and reduce programmatic costs, while optimizing the benefits for education, increasing access to care for the most marginalized, and encouraging girls to attend and stay in school.

Sustainable national school health programs depend on mainstreaming these programs into national policies and plans, as well as increasing national financing for SHN and strengthening cross-sectoral institutional implementation capacity. Existing resources, such as SABER and FRESH, can help the education sector identify policy gaps and opportunities, improve implementation, and scale up. HSBC and GSHS provide similar tools for guiding the school health policy decisions of the health sector.

This approach is most effective if the health sector retains responsibility for the health of children and the education sector retains responsibility for implementation. By working together, Ministries of Education and Health can promote better health and education through multisector SHN interventions.

\section{ACKNOWLEDGMENTS}

The author team would like to recognize Kwok-Cho Tang, formerly with the World Health Organization, and Meena Fernandes, Partnership for Child Development, for their important contributions to the chapter.

\section{NOTES}

World Bank Income Classifications as of July 2014 are as follows, based on estimates of gross national income (GNI) per capita for 2013:

- Low-income countries (LICs) $=$ US $\$ 1,045$ or less

- Middle-income countries (MICs) are subdivided:

a) lower-middle-income $=$ US $\$ 1,046$ to US $\$ 4,125$

b) upper-middle-income (UMICs) $=$ US $\$ 4,126$ to US $\$ 12,745$

- High-income countries (HICs) = US\$12,746 or more.

1. When an intervention involves the provision of food, the term school feeding is used. The term includes at least two modalities: in-school feeding, where children are fed in school; and take-home rations, where families are given food if their children attend school regularly. Nutrition is properly reserved for when a specific nutrition outcome is sought, such as correcting a micronutrient deficiency.

\section{REFERENCES}

Adelman, S., H. Alderman, D. O. Gilligan, and K. Lehrer. 2008. "The Impact of Alternative Food for Education Programs on Learning Achievement and Cognitive Development in Northern Uganda." International Food Policy Research Institute, Washington, DC.

Ahuja, A., S. Baird, J. Hamory Hicks, M. Kremer, and E. Miguel. 2017. "Economics of Mass Deworming Programs." In Disease Control Priorities (third edition): Volume 8, Child and Adolescent Health and Development, edited by D. A. P. Bundy, N. de Silva, S. Horton, D. T. Jamison, and G. C. Patton. Washington, DC: World Bank.

Alderman, H., J. R. Behrman, P. Glewwe, L. Fernald, and S. Walker. 2017. "Evidence of Impact of Interventions 
on Growth and Development during Early and Middle Childhood." In Disease Control Priorities (third edition): Volume 8, Child and Adolescent Health and Development, edited by D. A. P. Bundy, N. de Silva, S. Horton, D. T. Jamison, and G. C. Patton. Washington, DC: World Bank.

Atkins, P. 2007. “School Milk in Britain, 1900-1934." Journal of Policy History 19 (4): 395-427.

Baltussen, R., J. Naus, and H. Limburg. 2009. “Cost-Effectiveness of Screening and Correcting Refractive Errors in School Children in Africa, Asia, America, and Europe." Health Policy 89 (2): 201-15.

Benzian, H., B. Varenne, N. Stauf, R. Garg, and B. Monse. 2017. "Promoting Oral Health through Programs in Middle Childhood and Adolescence." In Disease Control Priorities (third edition): Volume 8, Child and Adolescent Health and Development, edited by D. A. P. Bundy, N. de Silva, S. Horton, D. T. Jamison, and G. C. Patton. Washington, DC: World Bank.

Boler, T. 2003. The Sound of Silence. London: ActionAid.

Brooker, S., S. Clarke, D. Fernando, C. Gitonga, J. Nankabirwa, and others. 2017. "Malaria in Middle Childhood and Adolescence." In Disease Control Priorities (third edition): Volume 8, Child and Adolescent Health and Development, edited by D. A. P. Bundy, N. de Silva, S. Horton, D. T. Jamison, and G. C. Patton. Washington, DC: World Bank.

Bundy, D. A. P. 2011. Rethinking School Health: A Key Component of Education for All. Directions in Development. Washington, DC: World Bank. doi:10.1596/978-0-8213-7907-3.

Bundy, D. A. P., L. J. Appleby, M. Bradley, K. Croke, T. D. Hollingsworth, and others. 2017. "Mass Deworming Programs in Middle Childhood and Adolescence." In Disease Control Priorities (third edition): Volume 8, Child and Adolescent Health and Development, edited by D. A. P. Bundy, N. de Silva, S. Horton, D. T. Jamison, and G. C. Patton. Washington, DC: World Bank.

Bundy, D. A. P., C. Burbano, M. Grosh, A. Gelli, M. C. H. Jukes, and others. 2009. Rethinking School Feeding: Social Safety Nets, Child Development, and the Education Sector. Directions in Development Series. Washington, DC: World Bank. doi:10.1596/978-0-8213-7974-5.

Bundy, D. A. P., N. de Silva, S. Horton, G. C. Patton, L. Schultz, and D. T. Jamison. 2017. "Child and Adolescent Health and Development: Realizing Neglected Potential." In Disease Control Priorities (third edition): Volume 8, Child and Adolescent Health and Development, edited by D. A. P. Bundy, N. de Silva, S. Horton, D. T. Jamison, and G. C. Patton. Washington, DC: World Bank.

Bundy, D. A. P., and S. Horton. 2017. "Impact of Interventions on Health and Development during Childhood and Adolescence: A Conceptual Framework." In Disease Control Priorities (third edition): Volume 8, Child and Adolescent Health and Development, edited by D. A. P. Bundy, N. de Silva, S. Horton, D. T. Jamison, and G. C. Patton. Washington, DC: World Bank.

Bundy, D. A. P., M. S. Wong, L. L. Lewis, and J. Horton. 1990. "Control of Geohelminths by Delivery of Targeted Chemotherapy through Schools." Transactions of the Royal Society of Tropical Medicine and Hygiene 84 (1): 115-20.
Chapman, K. 2006. "Using Social Transfers to Scale Up Equitable Access to Education and Health Services." Background paper, Scaling Up Services Team, DFID Policy Division. https://www.ids.ac.uk/files/dmfile/socialtransfersback.pdf.

Del Rosso, J. M., and T. Marek. 1996. Class Action: Improving School Performance in the Developing World through Better Health and Nutrition. Washington, DC: World Bank.

de Silva, N., S. Brooker, P. J. Hotez, A. Montresor, D. Engels, and others. 2003. "Soil-Transmitted Helminth Infections: Updating the Global Picture." Trends in Parasitology 19 (12): 547-51.

de Walque, D., L. Fernald, P. Gertler, and M. Hidrobo. 2017. "Cash Transfers and Child and Adolescent Development." In Disease Control Priorities (third edition): Volume 8, Child and Adolescent Health and Development, edited by D. A. P. Bundy, N. de Silva, S. Horton, D. T. Jamison, and G. C. Patton. Washington, DC: World Bank.

Drake, L., M. Fernandes, E. Aurino, J. Kiamba, B. Giyosa, and others. 2017. "School Feeding Programs in Middle Childhood and Adolescence." In Disease Control Priorities (third edition): Volume 8, Child and Adolescent Health and Development, edited by D. A. P. Bundy, N. de Silva, S. Horton, D. T. Jamison, and G. C. Patton. Washington, DC: World Bank.

Drake, L., C. Maier, and J. W. L. de Lind van Wijngaarden. 2007. Directory of Support to School-Based Health and Nutrition Programmes. London: Partnership for Child Development.

Drake, L., S. Singh, C. K. Mishra, A. Sinha, S. Kumar, and others. 2015. "Bihar's Pioneering School-Based Deworming Programme: Lessons Learned in Deworming over 17 Million Indian School-Age Children in One Sustainable Campaign.” PLoS Neglected Tropical Diseases 9 (11): e0004106. doi:10.1371/journal.pntd.0004106.

Drake, L., A. Woolnough, C. Burbano, and D. A. P. Bundy. 2016. Global School Feeding Sourcebook: Lessons from 14 Countries. London: Imperial College Press.

Durlak J. A., R. P. Weissberg, and A. B. Dymnicki. 2011. "The Impact of Enhancing Students' Social and Emotional Learning: A Meta-Analysis of School-Based Universal Interventions." Child Development 82 (1): 405-32.

Ettling, J. 1981. The Germ of Laziness: Rockefeller Philanthropy and Public Health in the New South. Cambridge, MA: Harvard University Press.

Fernandes, M., and E. Aurino. 2017. "Identifying an Essential Package for School-Age Child Health: Economic Analysis." In Disease Control Priorities (third edition): Volume 8, Child and Adolescent Health and Development, edited by D. A. P. Bundy, N. de Silva, S. Horton, D. T. Jamison, and G. C. Patton. Washington, DC: World Bank.

FRESH (Focusing Resources on Effective School Health), 2014. "Monitoring and Evaluation Guidance for School Health Programs: Eight Core Indicators to Support FRESH." http://www.unesco.org/new/en/education/themes /leading-the-international-agenda/health-education/fresh /me-indicators.

Gelli, A., U. Meir, and F. Espejo. 2007. "Does Provision of Food in School Increase Girls’ Enrollment? Evidence from 
Schools in Sub-Saharan Africa." Food and Nutrition Bulletin 28 (2): 149-55.

Graham, N., L. Schultz, S. Mitra, and D. Mont. 2017. "Disability in Middle Childhood and Adolescence." In Disease Control Priorities (third edition): Volume 8, Child and Adolescent Health and Development, edited by D. A. P. Bundy, N. de Silva, S. Horton, D. T. Jamison, and G. C. Patton. Washington, DC: World Bank.

Grigorenko, E. L., R. J. Sternberg, M. Jukes, K. Alcock, J. Lambo, and others. 2006. "Effects of Antiparasitic Treatment on Dynamically and Statically Tested Cognitive Skills over Time." Journal of Applied Developmental Psychology 27 (6): 499-526.

Guyatt, H. 2003. "The Cost of Delivering and Sustaining a Control Programme for Schistosomiasis and SoilTransmitted Helminthiasis.” Acta Tropica 86 (2-3): 267-74.

Hargreaves, G. C., and T. Boler. 2006. "Girl Power: The Impact of Girls' Education on HIV and Sexual Behaviour." Education and HIV Series 01, ActionAid International.

Hargreaves, J. R., C. P. Bonell, T. Boler, D. Boccia, I. Birdthistle, and others. 2008. "Systematic Review Exploring Time Trends in the Association between Educational Attainment and Risk of HIV Infection in Sub-Saharan Africa." AIDS 22: 403-14.

Horton, S., J. Waldfogel, E. De la Cruz Toledo, J. Mahon, and J. Santelli. 2017. "Identifying an Essential Package for Adolescent Health: Economic Analysis." In Disease Control Priorities (third edition): Volume 8, Child and Adolescent Health and Development, edited by Bundy, D. A. P., N. de Silva, S. Horton, D. T. Jamison, and G. C. Patton. Washington, DC: World Bank.

Jukes, M. C. H., L. Drake, and D. A. P. Bundy. 2008. School Health, Nutrition and Education for All: Levelling the Playing Field. Wallingford, U.K.: CABI Publishing.

Jukes, M. C. H., S. Simmons, and D. A. P. Bundy. 2008. "Education and Vulnerability: The Role of Schools in Protecting Young Women and Girls from HIV in Southern Africa." AIDS 22 (4): S41-S56.

LaMontagne, D. S., T. Cernuschi, A. Yabuku, P. Bloem, D. Watson-Jones, and others. 2017. "School-Based Delivery of Vaccines to 5 to 19 Year Olds." In Disease Control Priorities (third edition): Volume 8, Child and Adolescent Health and Development, edited by D. A. P. Bundy, N. de Silva, S. Horton, D. T. Jamison, and G. C. Patton. Washington, DC: World Bank.

Lassi, Z., A. Moin, and Z. Bhutta. 2017. "Nutrition in Middle Childhood and Adolescence." In Disease Control Priorities (third edition): Volume 8, Child and Adolescent Health and Development, edited by D. A. P. Bundy, N. de Silva, S. Horton, D. T. Jamison, and G. C. Patton. Washington, DC: World Bank.

Liddell, C., and G. Rae. 2001. "Predicting Early Grade Retention: A Longitudinal Investigation of Primary School Progress in a Sample of Rural South African Children." British Journal of Educational Psychology 71 (3): 413-28.

MacPhail, C., B. Williams, and C. Campbell. 2002. "Relative Risk of HIV Infection among Young Men and Women in a South African Township." International Journal of STD and AIDS 13 (5): 331-42.
Miguel, E., and M. Kremer. 2004. "Worms: Identifying Impacts on Education and Health in the Presence of Treatment Externalities." Econometrica 72 (1): 159-217.

Murray N. G., B. J. Low, C. Hollis, A. W. Cross, and S. M. Davis. 2007. "Coordinated School Health Programs and Academic Achievement: A Systematic Review of the Literature." Journal of School Health 77: 589-600.

Plaut, D., T. Hill, M. Thomas, J. Worthington, M. Fernandes, and others. 2017. "Getting to Education Outcomes: Reviewing Evidence from Health and Education Interventions." In Disease Control Priorities (third edition): Volume 8, Child and Adolescent Health and Development, edited by D. A. P. Bundy, N. de Silva, S. Horton, D. T. Jamison, and G. C. Patton. Washington, DC: World Bank.

Sarr, B., M. Fernandes, L. Banham, D. A. P. Bundy, A. Gillespie, and others. 2017. "The Evolution of School Health and Nutrition in the Education Sector 2000-2015." Frontiers in Public Health. https://doi.org/10.3389/fpubh.2016.00271.

Shackleton N, F. Jamal, R. M. Viner, K. Dickson, G. C. Patton, and C. Bonell. 2016. "School-Level Interventions to Promote Adolescent Health: Systematic Review of Reviews." Journal of Adolescent Health 58 (4): 382-96.

Tang, K. C., D. Nutbeam, C. Aldinger, L. St. Leger, D. A. P. Bundy, and others. 2009. "Schools for Health, Education and Development: A Call for Action." Health Promotion International 24 (1): 68-77.

UNESCO (United Nations Educational, Scientific and Cultural Organization). 2008. "EDUCAIDS Overviews of Practical Resources." http://portal.unesco.org/en/ev.phpURL_ID=36412 \&URL_DO=DO_TOPIC\&URL_SECTION=201.html.

- 2011. EFA Global Monitoring Report 2011: The Hidden Crisis: Armed Conflict and Education. Paris: UNESCO.

UNFPA (United Nations Population Fund). 2012. Status Report: Adolescents and Young People in Sub-Saharan Africa. Johannesburg: UNFPA http://www.prb.org/pdf12 /status-report-youth-subsaharan-Africa.pdf.

Verguet, S., A. Nandi, V. Filippi, and D. A. P. Bundy. 2017. "Postponing Adolescent Parity in Developing Countries through Education: An Extended Cost-Effectiveness Analysis." In Disease Control Priorities (third edition): Volume 8, Child and Adolescent Health and Development, edited by D. A. P. Bundy, N. de Silva, S. Horton, D. T. Jamison, and G. C. Patton. Washington, DC: World Bank.

Watkins, K., D. A. P. Bundy, D. T. Jamison, F. Guenther, and A. Georgiadis. 2017. "Evidence of Impact of Interventions on Health and Development during Middle Childhood and School Age." In Disease Control Priorities (third edition): Volume 8, Child and Adolescent Health and Development, edited by D. A. P. Bundy, N. de Silva, S. Horton, D. T. Jamison, and G. C. Patton. Washington, DC: World Bank.

WHO (World Health Organization). 1986. Ottawa Charter. Geneva: WHO.

- 1997. Promoting Health through Schools: Report of a WHO Expert Committee on Comprehensive School Health Education and Promotion. WHO Technical Report Series 870 . 
2015. "Summary of Global Update on Preventative Chemotherapy Implementation in 2015." Weekly Epidemiological Record 90 (49): 661-74.

. 2016a. "Global School-Based Student Health Survey." http://www.who.int/chp/gshs/en/.

- 2016b. "Health Behavior in School-Age Children." http://www.euro.who.int/en/health-topics/Life-stages /child-and-adolescent-health/child-and-adolescent-health2 /youth-friendly-services/health-behaviour-in-school -aged-children-hbsc2.-who-collaborative-cross-national -study-of-children-aged-1115.

WHO and CDC (U.S. Centers for Disease Control and Prevention). Not dated. "Global School Health Policies and Practices Surveys: Survey Implementation Workshop." WHO, Geneva, and CDC, Washington, DC. http://www .searo.who.int/entity/noncommunicable_diseases/events /global-shpps-survey-implementation-slides.pdf.
World Bank. 2002. Education and HIV/AIDS: Windows of Hope. Washington, DC: World Bank.

2011. "World Bank Education Sector Strategy 2020: Learning for All.” World Bank, Washington, DC. http:// siteresources.worldbank.org/EDUCATION/Resources /ESSU/Education_Strategy_4_12_2011.pdf.

. 2012. "What Matters Most for School Health and School Feeding: A Framework Paper." SABER Working Paper No. 3, World Bank, Washington, DC. http://wbgfiles .worldbank.org/documents/hdn/ed/saber/supporting_doc /Background/SHN/Framework_SABER-School_Health.pdf.

. 2016. "World Development Indicators." Education Statistics. World Bank, Washington, DC. http://databank .worldbank.org/data/reports.aspx? source=education -statistics- -all-indicators.

World Food Programme. 2016. "School Meals." World Food Programme, Rome. https://www.wfp.org/school-meals. 